\title{
A BUSCA DA TECNOLOGIA SUSTENTÁVEL: UM ESTUDO SOBRE RENZO PIANO
}

\author{
Celeste, Mariane'; Fernandes, Michelle'; Hashinaga, Adriana'; Santelo, Amanda; Costa, Korina² \\ Universidade do Oeste Paulista - UNOESTE, Curso de Arquitetura e Urbanismo, Presidente Prudente, SP.
}

\section{RESUMO}

Este trabalho tem como objetivo de analisar o pensamento High-tech em conjunto com o Eco-tech que veem respondendo as necessidades provocadas pelo esgotamento de fontes não renováveis e recursos naturais do planeta. Através do estudo de obras de Renzo Piano, arquiteto que obteve sucesso ao adotar essa vertente como base de seus projetos. As obras analisadas foram o Centro cultural Jean-Marie Tjibaou e o edifício London Bridge Tower, tais projetos demonstram a possibilidade do uso de uma complexa tecnologia, levando em consideração o bom funcionamento, a organização e a estética do edifício, além da preocupação ambiental. 0 estudo das obras que serão abordadas se deu através de pesquisas e leituras em textos e imagens.

Palavras-chave: Tecnologia. Sustentabilidade. Projeto. Tardomodernismo.

\section{THE SEARCH OF SUSTAINABLE TECHNOLOGY: A STUDY ON RENZO PIANO}

\begin{abstract}
This study has the object of analyze the High-tech thinking together with the Eco-tech, that have responded the needs inducing by the depletion of non-renewable resources and the planet's natural resources. Through the study of Renzo Piano's works, an architect who succeeded in adopting this line as the basis for their projects. The works analyzed were the Cultural Center JeanMarie Tjibaou and the London Bridge Tower building, such projects demonstrate the possibility of using a complex technology, considering the proper functioning, the organization and the aesthetics of the building, besides the environmental concerns. The study of the buildings that will be addressed, occurred through researches and readings in texts and images.
\end{abstract}

Keywords: Technology. Sustainability. Project. Tardomodernismo 


\section{INTRODUÇÃO}

A partir da década de 70 o modernismo começa a sofrer um declínio e paulatinamente vai deixando de lado o individualismo e populismo. Volta-se apreocupação de resolver os problemas da sociedade, dando espaço a liberdade criativa e a possibilidades projetuais e tecnológicas. Porém retomando algumas vertentes do próprio modernismo. Esse período se denomina tardomodernismo, que possibilitou a abertura de novos horizontes no campo da arquitetura, dando espaço para novas vertentes que se contrapõe com a ornamentação e a apelos visuais. Dentre as tendências da arquitetura deste século, destaca-se as produções com harmonia com o meio ambiente, e amais expressiva foi o high-tech.

$O$ high-tech consiste no pensamento de que "A arquitetura deve necessariamente expressar-se na forma estrutural e construtiva." (FRAMPTON, 2008, p.558). Ou seja, expondo o conteúdo tecnológico do edifício e fazendo o uso de materiais industrializados que prezam pela racionalidade na obra, otimização de matérias, mão de obra e, sobretudo tempo de produção, propondo a seu usuário espaços tradicionais, de máxima eficiência e aspectos estéticos e culturais.

Com uma sociedade em pleno crescimento tecnológico, as preocupações com impactos que a construção civil causa ao meio ambiente, os profissionais desta área passam a repensar certas técnicas construtivas, e baseadas na linha de pensamento do high-tech, surge uma nova geração de edifícios high-tech, através do Eco-tech, que consiste em métodos tecnológicos com preocupação ambiental, adotando princípios de sustentabilidade.

Dentre os representantes destes pensamentos, estão arquitetos como Richard Rogers, que se dedicou desde o inicio a alta tecnologia, se destacando pela exposição estrutural e mecânica de seus projetos. "Suas obras são totalmente desprovidas de elementos habituais, como portas e janelas, sendo verdadeiras "caixas-magicas", tecnicamente corretas. "(CASTELNOU, 2004, p. 92.)

Norman Foster dedicou-se ao projeto de grandes estruturas industriais, tendendo a uma produção mais clara entre a membrana e a estrutura do edifício, além disso, se preocupa com os detalhes arquitetônicos e pela qualidade de execução do projeto.

Jean Nouvel, considerado inovador e a frente do seu tempo, sendo avessas as características do modernismo e não influenciado por agentes externos em seus projetos. Tem como objetivo trazer o virtual pra mais próximo a realidade.

E por fim, Renzo Piano, estabelece a tecnologia como ponto de partida para seus projetos, é interessado pelas novidades tecnológicas e pela edificação ecológica, experimenta materiais inovadores, mas sempre priorizando o conforto e as necessidades do usuário. Piano é um grande produtor da arquitetura Eco-tech, presente nas obras que serão estudadas. 


\section{METODOLOGIA}

A metodologia basea-se numa investigação bibliográfica e se fundamentará numa abordagem qualitativa de pesquisa, utilizando-se como instrumento um levantamento bibliográfico e documental, que segundo Teixeira (2000, p. 137), busca a correlação entre a teoria e os dados, entre o contexto e a ação, a partir da compreensão dos fenômenos por meio de sua descrição e interpretação. Para o trabalho com o estudo do tipo de levantamento bibliográfico ocorrerá inicialmente um levantamento das principais produções no contexto nacional de estudos, considerando a peculiaridade do objeto de estudo.

Desse modo, percebe-se que a pesquisa qualitativa vale-se do método indutivo, segundo o qual parte da observação, da análise dos fatos particulares, dos registros para compor um quadro compreensivo para então constituir a generalização universal, ou seja, a teoria. O processo de indução vale-se do princípio do empirismo, no qual o conhecer é dar significado à realidade (KÖCHE, 1997, p. 62).

\section{Renzo Piano}

Renzo Piano nasceu em Setembro de 1937, em Gênova, o antigo porto italiano, no Mediterrâneo, estudou em Florença e em Milão; onde trabalhou no escritório de Franco Albini e experimentou as primeiras rebeliões estudantis da década de 1960.

Nascido em uma família de construtores, visitas frequentes ao seu pai canteiros de obras de Carlo deu-lhe a oportunidade de combinar a experiência prática e acadêmica, se formou entãona Universidade Politécnica de Milão, em 1964. De 1965 a 1970, combinado seu primeiro trabalho experimental com seu irmão Ermanno juntamente com inúmeras viagens para a GrãBretanha e os Estados Unidos.

Em 1971, o escritório Piano \& Rogers começa a atuar em Londres com Richard Rogers; juntos, eles ganharam o concurso para o Centro Pompidou e posteriormente muda-se para Paris, á partir disto, desta parceria surge uma série de projetos deedifícios naltália e Inglaterra.

Segundo Melin (2013):

Embora não seja reconhecido por nenhum estilo pessoal, a variada obra de Piano - doCentre Pompidou, projetado em parceria com Richard Rogers quando tinha apenas 35 anos, ao reverenciado MenilCollection em Houstou, ou a torre The Shard em Londres - mostra seu domínio sobre os elementos menos tangíveis da arquitetura, como a luz e o ar. 
Desde o início dos anos 1970 para os anos 1990, ele trabalhou com o engenheiro Peter Rice, compartilhando o Atelier Piano \& Rice 1977-1981. Seus projetos muitas vezes incluem parceria com diversos arquitetos.

Como a maioria das obras projetadas por membros do movimento "High-Tech", Piano estabelece a tecnologia como ponto de partida para seus projetos. Mas ultimamente tem sido diferente, ele modificou suas tentativas de gerar um caráter arquitetônico baseado somente em formas tecnológicas, mas também apresenta preocupação com o conforto e as necessidades do usuário. Em seus trabalhos mais recentes, Piano aplicou seus experimentos estruturais para uma série de projetos sociais e cívicos.

Reconhecimentos das suas realizações incluem prêmios como o RIBA Real Medalha de Ouro de Arquitetura em 1989, o Praemium Imperiale em Tóquio, em 1995 e o Prêmio Pritzker de Arquitetura em 1998.

\section{Centro Cultural Jean-Marie Tjibao}

A criação de um projeto icônico para a civilização Kanak, sem cair no "folclorismo", foi o maior desafio de Piano, quando em 1991, projeta o que seria o centro da preservação cultural do povo Kanak, o Centro Cultural Jean-Marie Tjibao, na cidade de Nouméia, á 10 km da capital do país.

No intuito de criar uma obra que fosse diretamente ligada aos costumes Kanak, Piano buscou inspiração na forma das ocas e objetos de adornos deste povo e o resultado foi uma estrutura orgânica com materiais aparentemente naturais, embora esta mesma produção seja uma das mais expressivas obras do Eco-tech.

Segundo Sacchetto (2011):

A influência de traços culturais advindos do autor do projeto, em toda sua formação teórica assim como experiência prática fez do C.C.T. uma obra soberana que não nega a essência cultural, mas a extrai de maneira a criar uma relação de hierarquias entre as culturas envolvidas.

Á partir disto pode-se perceber que a crítica do pesquisador ao Centro Cultural é positiva quanto ao traçado que une o tecnológico e o passado; opinião similar ás já apresentadas foi expressa pelo autor a seguir, onde segundo Hülskath (2012) "Esse edifício é visto como ponto culminante de um movimento de décadas de valorização patrimonial indígena da Melanésia e como gesto significativo do govêrno francês para com uma cultura que muito sofreu com a colonização da Nova Caledônia.", portanto o renome de Renzo é fortemente elevado quando este 
projeto é o assunto. Sua preocupação com o impacto ambiental, bem como em não destoar do entorno, elevou este projeto do high-tchpara o eco-tech, que norteia uma produção consciente dos seus impactos ao meio ambiente; e embora, como já mencionado anteriormente, esta obra seja aparentemente feita de materiais efêmeros como uma oca, na verdade sua complexidade vai muito além, tendo Piano, criada um sistema de sustentação digna do pós-revolução industrial, baseado no uso de metais e encaixes, haja vista sua grande resistência á tração e compressão.

Esta obra traz a organicidade e a proximidade do projeto com a cultura Kanak, maximizando em tamanho físico e memória a obra desta civilização, obra esta que "é conduzida de forma a produzir uma arquitetura comunicativa, indutora, influenciadora e imponente para com a cultura local. A relação de superioridade e o conflito de culturas são elementos sintetizados numa leitura ordenada à evocação de uma obra globalizada. A obra de Nova Caledônia remete a exploração de elementos básicos - a cultura e a tecnologia - que, quando cruzados conformam o Centro Cultural como uma obra internacional, implantada num contexto especifico e peculiar capaz de se impor a esse mesmo contexto, por conta de sua linguagem de expressão arquitetônica e seu enquadramento histórico-cultural." (SACCHETTO, 2011).

\section{London Bridge Tower}

O London Bridge Tower, também conhecido como The Shardfoi inaugurado em 2012, e fica localizado ao lado da estação de London Bridge, na cidade de Londres.Segundo o arquiteto, este projeto foi uma resposta à uma visão urbana do prefeito de Londres, Ken Livingstone e à sua politica de desenvolvimento da alta densidade encorajando em nós o transporte coletivo. (PIANO, 2015. s/p.) Baseando-se na proximidade de transportes públicos, e desencoraja o uso do carro e consequentemente ajuda a reduzir o congestionamento do tráfego na cidade.

Com sua altura de trezentos e dez metros e seus setenta e dois pavimentos, torna-se um elemento dominante do novo perfil urbano e agiganta uma forma histórica, a agulha que caracterizou o panorama urbano do século XVII em diante(BENEVOLO, 1923.).

Construído na área da London Bridge, o The Shard é um contraponto à arquitetura da área, marcada por edifícios históricos de baixa estatura. "O edifício conta uma história completamente diferente aos demais edifícios ao redor." (ZANETTE, 2012. s/p.). A diversidade é uma característica do local. Londres há muito tempo mescla o moderno com o tradicional. Para o arquiteto o edifício reflete características do bairro. 
O London Bridge Tower é um edifício de uso misto de residências e escritórios. Sendo assim utilizadas 24 horas por dia. A planta como forma de um triangula irregular mantem-se desde a base até a parte superior, reduzindo continuamente sua área.

As entradas para cada uso são separadas, dando identidade, privacidade e independência dos espaços. São 44 elevadores, 4 escadas e toda a circulação vertical é realizada pelo core do edifício, de concreto moldado in loco. (ZANETTE, 2012. s/p.)

O prédio também adotou outras medidas que levaram em conta o meio ambiente. A persiana mecânica e a fachada eficiente de vidro duplo com baixo teor de ferro e clara como um cristal, por exemplo, aproveitam ao máximo a luz natural e procuram criar um ambiente interno com temperatura estável em qualquer época do ano.

Segundo Zanette (2012. s/p.):

Em dias nublados, a persiana instalada entre as camadas de vidro ficará aberta, ao contrário dos dias ensolarados, quando será fechada. E o fato de Londres estar em área de clima temperado, com temperaturas geralmente entre $5^{\circ} \mathrm{C}$ e $20^{\circ} \mathrm{C}$, facilita o controle, proporcionando que o ambiente não fique muito quente no verão, nem esfrie no inverno.

O London Tower Bridge tem sido o estímulo para grande parte da regeneração da área que por 20 anos foi considerada como uma das áreas mais pobres da cidade, ganhando novos estabelecimentos, como edifícios comerciais, residenciais e galerias de arte.

\section{CONCLUSÃO}

Ao analisarem-se as obras, percebe-se que Renzo Piano é um percursor do Eco-tech, se preocupa com o conforto e as necessidades do usuário, mas também considera importantes as questões ambientais e o impacto que sua obra causará no local que será inserida. Como por exemplo, na obra London Bridge, o edifício fica localizado ao lado da estação de metrô, incentivando as pessoas a utilizar o transporte coletivo, evitando trânsito e contribuindo na diminuição dos gases poluentes gerados pelos carros.

Dessa forma em suas obras utiliza elementos tecnológicos como referenciais estéticos, mas sempre tem em mente que é preciso procurar utilizar materiais que atendam o equilíbrio ambiental e ao mesmo tempo satisfazendo o bem estar de seus usuários. 


\section{REFERÊNCIAS}

BARDA, Marisa. Vitruvius. The New York Times. Nov.2000.ano 01.Disponível em:<http://www.vitruvius.com.br/revistas/read/drops/01.001/1565>. Acesso em: 23 de março de 2015.

BARDA, Marisa. Revista AU. Nova atração na Times Square. Jan.2008.ed.166. Disponível em:<http://au.pini.com.br/arquitetura-urbanismo/166/uma-nova-atracao-na-times-square70729-1.aspx.>. Acesso em: 23 de março de 2015.

BENÉVOLO, L. A arquitetura no novo milênio. São Paulo: Estação Liberdade, 2007. Capítulo IV. Hülskath, H. O revelar do sentido oculto dos vegetais na tradição kanak e o processo criador:0 homem vegetal na arte da Nova Caledônia à luz do movimento da união do vegetal no Brasil. Revista Brasil-Europa - Correspondência Euro-Brasileira. V. 136/21. Fev 2012. Disponível em: <http://www.revista.brasil-europa.eu/136/Tjibaou-Vegetais-e-Cultura.html>. Acesso em: 19 de março de 2015.

HOWARTH, Thomas. Apud PIANO, Renzo. Renzo Piano Building Workshop.Disponívelem: <http://www.rpbw.com/>. Acessoem: 24 de março de 2015.

JOHNSON, Kirk. The New York Times.Soaking Up the Sun to Squeeze Bills to Zero. Feb.2011. Disponível em: <http://www.nytimes.com/2011/02/15/science/15building.html>. Acesso em: 23 de março de 2015.

KÖCHE, J. C. Fundamentos de metodologia científica: teoria da ciência e iniciação à pesquisa. 22 . ed. São Paulo: Vozes, 2004.

LINHARES, Juliana. Revista veja. A leveza do poeta concreto. out.2008.ed.2083.Disponivel em: <http://veja.abril.com.br/221008/p_128.shtml>. Acesso em: 23 de março de 2015.

MELIN, Gili. Feliz Aniversário Renzo Piano! ArchDaily online. Disponível em<http://www.archdaily.com.br/br/01-140854/feliz-aniversario-renzo-piano> Acesso em: 27 de Março de 2015.

PIANO, Renzo.Renzo Piano Building Workshop.Disponível em: <http://www.rpbw.com/>. Acesso em: 24 de março de 2015.

TEIXEIRA, E. As três metodologias. 2a .ed. São Paulo: Vozes, 2000.

SACCHETTO, C. O papel da cultura local no projeto tecnológico: Centro Cultural Jean-Marie Tjibaou - Renzo Piano. Vitruvius. $2011 . \quad$ Disponível em: http://www.vitruvius.com.br/revistas/read/arquitextos/11.128/3568>. Acesso em: 19 de Março de 2015.

ZANETTE, Emerson. Revista AU. Renzo Piano projeta o The Shard, em Londres, edifício mais alto da União Europeia,ago. 2012. Ed. 221. Disponível em: <http://au.pini.com.br/arquiteturaurbanismo/221/renzo-piano-projeta-o-the-shard-em-londres-edificio-mais-264538-1.aspx>.

Acesso em: 22 de setembro de 2015. 